\title{
A inclusão de projetos, de práticas didáticas e de transposição didática na formação docente
}

\author{
Cleide Inês Wittke ${ }^{1}$
}

\section{Resumo}

Este artigo teve sua origem a partir de práticas cotidianas no ensino de português, por meio de atividades de leitura, oralidade, escrita e gramática, vivenciadas no ensino básico e, posteriormente, na formação de professores de línguas em uma universidade federal do sul do país. As práticas docentes e as pesquisas efetuadas sobre o ensino de língua e a formação desse profissional mostram a necessidade de redimensionar o objeto de estudo/ ensino e também o modo de abordá-lo, o que impacta na reformulação dos currículos dos cursos de Letras. Com o objetivo de refletir sobre o tema e apontar caminhos a essa reconstrução, sob uma perspectiva interacionista sociodiscursiva, defendemos a formação de um profissional pesquisador, reflexivo e autônomo. A universidade tem o compromisso de preparar o professor de modo que saiba trabalhar com o gênero textual, abordando-o a partir de diferentes estratégias, desenvolvendo a competência leitora e a capacidade de produzir textos orais e escritos (MARCUSCHI, 2008, 2010; SCHNEUWLY, DOLZ, 2010). Vemos a ênfase à didática e à transposição didática, bem como o estímulo à realização de pesquisas, projetos e o diálogo com o professor em atuação como possibilidades de concretizar as mudanças desejadas.

Palavras-chave: Formação docente. Pesquisa. Interação verbal

\footnotetext{
1 Professora Associada na Universidade Federal de Pelotas, atuando na Graduação e na Pós-Graduação. Doutora em Letras pela Pontifícia Universidade Católica do Rio Grande do Sul, tendo realizado Estágio Pósdoutoral em Didática das Línguas na Universidade de Genebra.
} 


\section{Considerações iniciais}

O contexto do ensino de língua materna no sistema educacional brasileiro mostra que seu processo não tem produzido os efeitos desejados. Resumindo, não vem ocorrendo em forma de atividades frequentes e produtivas de interação verbal, tanto na modalidade falada quanto na escrita. Essa realidade motiva não só pesquisadores, mas também professores a questionarem e investigarem quais são as principais razões para que tal prática escolar venha obtendo resultados tão improdutivos. Esse quadro social traz muitos questionamentos, tais como: Quais são os problemas enfrentados no ensino de língua portuguesa em nossas escolas? Quais são os caminhos viáveis para que essa prática pedagógica se torne um processo que desenvolva a capacidade comunicativa do aluno, dando-lhe segurança para que possa interagir de modo adequado nas mais variadas situações sociais, seja lendo, falando ou escrevendo?

Há várias décadas, vemos muitos estudiosos da linguagem, estrangeiros e brasileiros, preocupados com os problemas educacionais e pesquisando sobre o tema, na busca de soluções para qualificar o ensino de língua. Dentre eles, citamos Geraldi (2006), Perrenoud (1999), Marcuschi (2008, 2010), Travaglia (2003, 2016), Antunes (2009, 2014), Schneuwly e Dolz (2009, 2010), Bronckart (2012), Koch e Elias (2016). Esses autores chegaram ao consenso de que é de extrema importância que o texto seja eleito como objeto de ensino. Nessa perspectiva, o trabalho com o texto demanda que o docente planeje e realize exercícios práticos desenvolvendo o uso da língua, levando em conta suas variações, de modo que o aluno possa tomar consciência e aperfeiçoar o domínio linguístico e discursivo nas diferentes situações sociais (BAKHTIN, 1992).

Concordamos com Perrenoud (1999), quando o autor defende ser preciso formar um professor que, além de investigar e refletir sobre o saber em construção, também construa uma prática reflexiva sobre sua atuação docente diária, repensando e reorganizando seu agir na sala de aula, e também fora dela. Nesse sentido,

O docente que consegue associar o trabalho de pesquisa a seu fazer pedagógico, tornando-se um professor pesquisador de sua própria prática ou das práticas pedagógicas com as quais convive, estará no caminho de aperfeiçoar-se profissionalmente, desenvolvendo uma melhor compreensão de suas ações como mediador de conhecimentos e de seu processo interacional com os educandos. Vai também ter uma melhor compreensão do processo de ensino e de aprendizagem (BORTONI-RICARDO, 2008, p. 32-33). 
Conforme já orientam os Parâmetros Curriculares Nacionais (BRASIL, 1998, 1999), há mais de duas décadas, o ensino de língua como ação social, como prática de interação deve ser planejado e ministrado por meio de textos com o objetivo de desenvolver as competências (as capacidades de linguagem): leitora, de produção oral e escrita, bem como de análise linguística e gramatical. Uma abordagem sob essa perspectiva demanda a reformulação do conceito de língua, mas principalmente do papel que o gênero textual e o ensino de gramática assumem nessas aulas. Urge que o professor substitua os tradicionais exercícios de identificação e classificação das regras da língua, com ênfase na nomenclatura, pelo trabalho com a análise linguística, a leitura, a oralidade e a escrita, a partir de diferentes gêneros textuais. No caso da análise linguística, essa poderia ser abordada à medida que os elementos gramaticais atuam na produção de sentidos, no texto, ou seja, no discurso.

Cabe ressaltar que não defendemos uma postura radical, ou seja, um ensino de português sem qualquer referência à metalinguagem; ao contrário, essa atividade é importante, mas seu estudo precisa ser realizado de modo pontual ${ }^{2}$ e com o objetivo de sanar dificuldades no uso que o aluno faz da língua, seja falando ou escrevendo. Nessa ótica, haverá momentos no processo, principalmente durante a produção textual escrita, que o conhecimento e o domínio consciente das regras da língua serão fundamentais para que o aluno seja capaz de usar o português adequadamente, nas mais variadas instâncias discursivas.

Sob um enfoque histórico e sociointeracionista (BAKHTIN, 1992; BRONCKART, 2012), vemos a aula de português como um espaço onde o aluno constrói e desconstrói variados tipos de textos (os quais circulam socialmente como gêneros textuais) enquanto interage com o outro, com a intenção de se comunicar, seja lendo, falando e/ou escrevendo. Através de estratégias de leitura, produção oral e escrita, o professor cria oportunidades para que o aluno analise textos prontos e também construa novos. A concepção sociointeracionista altera o papel do professor de português, pois ele passa a ser o mediador entre o texto e o aluno: um facilitador do processo de aprendizagem. Mas estão os cursos de Letras, especialmente os professores formadores de tais cursos, cientes desse papel e preparados para orientar os licenciandos a serem mediadores do conhecimento? Vale lembrar aqui o questionamento feito por Cordeiro (WITTKE; CORDEIRO, 2016),

\footnotetext{
${ }^{2}$ De modo pontual significa selecionar uma dificuldade apresentada pelos alunos, especialmente nos textos por eles produzidos, e trabalhar esse elemento da gramática. Pode ser o uso da vírgula, da concordância, verbal ou nominal, da conjugação de um tempo verbal, ou outra questão dessa natureza.
} 
em entrevista dada à autora deste artigo: $O$ que é ser um professor mediador, um construtor do conhecimento? Estendendo essa questão, indagamos: estão os professores universitários abrindo espaço para dialogar com o profissional em serviço nas escolas? A postura de um professor mediador implica alterações nos cursos de Letras.

\section{Mudança de perspectiva nos currículos de Letras e seu efeito na formação docente}

O fato de assumir o conceito de língua como um trabalho de interação social (sociointeracionista) implica diretamente em mudanças no currículo dos cursos de Letras, o que demanda reorganização em suas disciplinas, ementas e conteúdos programáticos a serem trabalhados ao longo da formação acadêmica. Também entendemos, assim como há várias décadas Possenti (2002), Geraldi (2006) e Dolz (WITTKE; DOLZ, 2015) defendem ser fundamental que o futuro professor seja orientado a assumir uma postura de pesquisador.

Estamos falando de um profissional que transforma sua sala de aula em um laboratório, onde o saber não seja meramente transmitido, mas construído por meio de hipóteses que, às vezes são comprovadas, outras vezes, rejeitadas. O fundamental é que se trabalhe com a criação de problemas e com a construção sistemática de respostas ou caminhos possíveis a determinadas soluções, pois isso estimula e instiga o aluno a estudar, ou seja, a construir conhecimento. Podemos citar o estudo do pronome todos como exemplo, pois, segundo a gramática normativa, ele é indefinido, todavia, em um contexto específico, tal como em: Ontem, eu e meus amigos Paulo, Maria e Márcia fomos na casa da Mariana. Foi uma noite muito divertida e todos voltaram felizes para seus lares. Nesse caso, podemos identificar as pessoas a quem "todos" se refere, portanto, o sentido que ele produz não se configura como um pronome indefinido.

A tomada de posição para formar um professor pesquisador reforça a importância da reestruturação curricular (teórica e metodológica) na universidade, pois é na sua formação inicial que o acadêmico constrói os alicerces de sua identidade de professor e das práticas didático-pedagógicas que desenvolverá ao longo de sua experiência profissional, as quais devem ser constantemente aperfeiçoadas com atividades de formação continuada (GUIMARÃES; CARNIN; KERSCH, 2015). Precisamos, então, pensar e reorganizar os currículos dos cursos de Letras de modo que os licenciandos trabalhem por meio de 
projetos, os quais ora podem ser desenvolvidos no meio acadêmico, ora no ambiente escolar, em parceria com o professor do ensino básico. Essa proposta pode ser organizada de forma que os projetos sejam vinculados aos estágios de observação, intervenção comunitária e docência, ou a outra disciplina, ou ainda como um projeto independente.

Sob a perspectiva de um trabalho sociointeracionista e com o desejo de formar um professor pesquisador, que investiga e constrói conhecimento, juntamente com o aluno, faz-se necessário criar oportunidades para que o estudante desenvolva essa competência durante sua formação inicial, por meio de atividades desenvolvidas na sala de aula e em projetos de pesquisa, ensino e extensão. Mas como construir um caminho seguro à formação do futuro professor em parceria com o profissional do ensino básico, tendo a qualidade da educação como meta comum?

Nesse contexto, quais estratégias e quais atividades podem oferecer os cursos de Letras em um intercâmbio entre a universidade e a escola? Considerando que, geralmente, realidade vivenciada em uma universidade federal do sul do país, as disciplinas dos dois primeiros anos são voltadas à formação do saber do professor (saber a ensinar, segundo SCHNEUWLY, 2014), desenvolvendo conhecimentos do núcleo duro: fonética, morfossintaxe, semântica e fundamentos teóricos da linguística e da literatura (no caso do curso Licenciatura em Português e Literatura), entendemos que as disciplinas voltadas diretamente ao ensino, à transposição didática e à própria didática, incluindo os estágios, apresentam mais flexibilidade e podem ofertar com mais frequência projetos de ensino, pesquisa e extensão, direcionados ao ensino de língua na escola. Essas últimas disciplinas, por terem um objetivo didático, voltado ao saber para ensinar (SCHNEUWLY, 2014), abrem mais possibilidades para trabalhar por meio de projetos.

A partir desse enfoque, sugerimos a realização de seminários, palestras, oficinas e cursos organizados pelos próprios acadêmicos (com orientação de um ou mais professores formadores em projetos a serem desenvolvidos nas próprias disciplinas ou via extensão) e voltados à comunidade escolar, tanto a professores quanto a alunos. Essa proposta possibilita que o licenciando vá até a escola para conversar com os professores e faça um diagnóstico da realidade vigente, descobrindo o que já está funcionando, mas, especialmente, identificando os aspectos que precisam ser mudados para, em conjunto, elaborar projetos que possam melhorar a qualidade do ensino e da aprendizagem da língua. Cabe aqui fazer referência ao Programa Institucional de Bolsa de Iniciação à Docência 
(PIBID), oferecido pelo Governo Federal, via Capes, a Instituições de Ensino Superior, que há oito anos vigora em nossa universidade pública, com resultados bastante produtivos. Esse projeto institucional consiste em uma excelente oportunidade para que o docente, ainda em formação, seja imerso na sala de aula e possa vivenciar experiências diárias da ação docente.

O Programa conta com projetos disciplinares (de área) e também interdisciplinares, envolvendo todos os cursos engajados na proposta governamental. Ousamos dizer que, embora ainda de modo singelo, começamos a colocar em prática o antigo desejo de integrar o licenciando na realidade escolar. Dessa forma, conseguimos colocá-lo em diálogo com o professor em serviço, oportunizando a solidificação de sua formação.

A partir de nossa proposta, sugerimos que, na primeira etapa, sejam realizados estudos de fundamentação teórica e didático-pedagógica de obras que abordam o ensino de língua materna (BRASIL, 1998; GERALDI, 2006; MARCUSCHI, 2008; ANTUNES, 2014). Na segunda fase, os acadêmicos vão à escola e observam a realidade vigente. Ao interagir com os professores (via conversa informal ou entrevista mais estruturada, ou ainda por meio de outro instrumento previamente estabelecido), o estudante de Letras identifica as principais dificuldades e problemas encontrados na prática do ensino de língua. Ao mesmo tempo, o acadêmico traz reflexões e sugestões apontadas pelos alunos e pelos professores.

$\mathrm{Na}$ terceira etapa, propomos um estudo sobre os dados coletados, selecionando as principais questões a serem trabalhadas. Depois, construímos estratégias (envolvendo leitura e produção textual) e atividades adequadas para sanar as dificuldades observadas no ensino e na aprendizagem de língua. Finalizamos o projeto através de cursos, palestras, seminários e oficinas com vistas a refletir sobre o tema e desenvolver atividades que possam aperfeiçoar o ensino do português, enquanto processo de interação verbal.

\section{O papel da didática na formação inicial: uma postura metodológica}

Tomando como base os currículos de boa parte dos cursos de Letras da universidade brasileira, em especial, da universidade federal onde trabalho, no sul do país, e também das experiências vivenciadas com colegas da área em eventos em todo o Brasil 
(ANPOLL, SIGET, InPLA), acredito que um dos problemas cruciais na formação de nossos professores de língua para o ensino básico está na pouca valorização e na pouca carga horária destinada a disciplinas voltadas ao saber para ensinar (de natureza didática, psicológica, pedagógica e cultural). Entendemos que o saber voltado à formação docente o saber para ensinar - é fundamental à ação do professor, pois é essencial para capacitá-lo a desempenhar com excelência sua profissão. Em grande parte das universidades brasileiras, esse saber acaba sendo diluído em algumas disciplinas de estágio (geralmente, três ou quatro), as quais o acadêmico realiza a partir do quarto ou quinto semestre. Todavia, os resultados obtidos a partir dessa formação, cujo efeito se dá no ensino e na aprendizagem de alunos do ensino básico, principalmente na rede pública, mostram necessidade de mudanças, pois parece que a carga horária vigente não tem sido suficiente para capacitar o professor no domínio do saber para ensinar.

Conforme o didaticista Schneuwly (WITTKE; SCHNEUWLY, 2016), é através dos saberes desenvolvidos nas diferentes disciplinas de didática que o professor se situa no campo profissional, tomando consciência de seu trabalho de educador. Para ter domínio sobre o agir docente, ou seja, para saber como agir no decorrer de suas aulas, o professor precisa ter noções de ciências da educação, de sociologia e de psicologia. Enfim, ele deve ter domínios e conhecimentos que o habilitam a lidar social e culturalmente com a realidade de seus alunos.

Tomando como base o sistema tripartido de formação docente realizado na Universidade de Genebra (UNIGE), apostamos na tese de que a implementação de mais disciplinas didáticas nos cursos de licenciatura, com foco na história da educação, na psicologia e na sociologia, bem como em técnicas, domínios e conhecimentos próprios do agir do professor pode ser uma medida para aperfeiçoar a formação nos cursos de Letras, repercutindo na qualidade do ensino de língua na rede educacional brasileira. No que diz respeito à formação inicial na universidade supracitada, Schneuwly et al. (2012, p. 451) explicam que o estágio de docência é assumido por um professor formador universitário e por um professor formador de terreno (formateur de terrain ${ }^{3}$. Este último acompanha

\footnotetext{
${ }^{3}$ No sistema da educação suíça, mais especificamente na Universidade de Genebra, os formadores de terreno são professores encarregados por uma ou mais horas com o objetivo de acompanhar os estagiários sob sua responsabilidade, em colaboração direta com professores formadores das disciplinas de estágios. A avaliação do estagiário é feita de forma conjunta, através de encontros com as três partes envolvidas: professor formador, o professor de terreno e o estagiário (SCHNEUWLY et al., 2012, p. 455).
} 
regularmente o estagiário em sua prática docente, e, como há troca, intercâmbio com a equipe de pesquisa correspondente à disciplina de estágio, isso permite múltiplos movimentos de alternância entre a formação na prática escolar e o ensino na universidade. Segundo o didaticista suíço, esses movimentos se configuram assim: 1) formação profissional prática no ambiente escolar; 2) formação teórico-prática articulando a formação de terreno, que inclui a análise das práticas (didáticas e abordagens transversais) e a pesquisa; 3) pesquisa científica sobre as práticas em todas as dimensões.

Sob um olhar como observador externo, principalmente se comparado com o processo de formação na universidade onde atuo, o sistema de formação na UNIGE pode parecer plenamente adequado, mas, em entrevista concedida à autora deste artigo, o professor e pesquisador Dolz (WITTKE; DOLZ, 2015) esclarece que os fundamentos em ciências da educação e em psicologia não são suficientes para a didática das línguas. No entender do estudioso, o ensino e a aprendizagem de línguas demanda um trabalho de operacionalização dos conceitos que podem servir tanto para o licenciando em suas práticas futuras, também para o professor formador já em serviço na escola, quanto para o professor formador universitário nas suas pesquisas.

Ao falar sobre o processo de formação inicial na UNIGE, Cordeiro (WITTKE; CORDEIRO, 2016) diz haver duas disciplinas de Didática do Francês (I e II), nos primeiros anos do curso generalista. Enquanto no primeiro ano os futuros professores aprendem a elaborar uma apresentação de uma situação de comunicação, no segundo ano eles são orientados a elaborar um módulo de produção textual e outro de ortografia, independente do primeiro. Esses módulos são pré-determinados nas ementas da disciplina.

Tanto no Francês I quanto no II, nas duas primeiras semanas de aula os acadêmicos são orientados a irem até a escola, conversar com o professor, assistindo a suas aulas, entrevistando-o, se necessário, e escolhendo o gênero de texto a ser trabalhado posteriormente. Depois de assistirem às aulas na escola, os licenciandos retornam à universidade para, juntamente com o professor formador, dar sequência às atividades da disciplina.

No caso da disciplina de Francês I, os acadêmicos são orientados a produzir uma apresentação de uma situação de comunicação para ser aplicada na escola. No Francês II, considerando que os licenciandos já fizeram no ano anterior a apresentação da produção inicial, agora são orientados para trabalhar com um novo gênero, em outro ano, com um 
professor diferente. O sistema é organizado de modo que os futuros professores possam compreender como funciona a progressão espiral na escola. Nas duas últimas semanas de terrain, os acadêmicos analisam as produções feitas pelos alunos e elaboram um módulo a ser desenvolvido em duas semanas: um módulo de produção textual do gênero em foco e outro, independente do primeiro, de ortografia.

A partir do exemplo de formação docente descrito, no qual a didática é fundamental, tanto nas orientações do professor formador quanto na aplicação das atividades elaboradas em sala de aula, continuamos nossa reflexão definindo e delimitando o objeto de estudo/ensino, com foco no saber a ser ensinado na formação do professor de língua.

\section{O objeto de ensino na formação inicial do professor}

Para Bronckart (2012), o professor realiza uma ação social que é diretamente influenciada pelo contexto em que atua, portanto, ele deve entender e acompanhar as mudanças sociais de sua época, ajustando-as à sua prática de ensino. Quando isso não ocorre, seu agir fica desatualizado e o profissional da educação não consegue atingir as metas de ensino, nem de aprendizagem de leitura e produção de textos orais e escritos, as quais são demandadas pela sociedade letrada. Cabe, então, definir quais são os saberes e o saber-fazer essenciais para formar um professor de língua seguro e competente, preparado para realizar um ensino de qualidade.

Temos consciência de que o professor precisa dominar os saberes a ensinar, isto é, conhecer e dominar estratégias de leitura, de produção escrita e oral, conhecimentos do processo de comunicação e do uso linguístico, de vocabulário, de ortografia, de conhecimentos literários e culturais, no entanto, também se faz necessário construir uma formação consistente sobre os saberes para ensinar (SCHNEUWLY; CORDEIRO; DOLZ, 2005). Além de ter domínio do conteúdo oficialmente reconhecido pelas instituições de ensino, manifestado nas ementas das disciplinas de referência e nos planos de estudo, também precisa conhecer e dominar técnicas próprias dos saberes para ensinar, quer dizer, práticas didático-pedagógicas que desenvolvem a competência no agir profissional. 
É nesse sentido que Schneuwly et al. (2012) mostram que a profissão de professor é a única que apresenta duplo estatuto na sua formação: um voltado especificamente a questões sobre o saber a ser ensinado (domínio e conhecimento dos conteúdos próprios das disciplinas de língua, literatura e suas especificidades), e outro direcionado ao saber para ensinar (domínio de técnicas e modos de ensinar os conteúdos, englobando conhecimentos em psicologia, didática, pedagogia e educação). Quais são, então, os objetos de ensino apropriados a serem trabalhados nas disciplinas de referência, na formação docente?

\section{O objeto a ensinar}

O conhecimento e o domínio do objeto de ensino são de fundamental importância para que o professor entenda e seja capaz de realizar uma prática docente de qualidade e com bons resultados na aprendizagem dos alunos. Para Petitjean (1998), Halté (1998) e Schneuwly (2014), estudiosos da teoria de Transposição Didática, o objeto do saber sofre várias transformações até se configurar em objeto de ensino, material apropriado para ser ensinado na escola.

Segundo Chevallard (1985), fundador dessa teoria, o saber científico (savant) é descontextualizado do meio científico (ou mesmo técnico) e recontextualizado como objeto de ensino, no ambiente escolar, vindo a sofrer novas transformações até se efetuar como objeto ensinado (SCHNEUWLY; DOLZ, 2009). No ponto de vista desses dois didaticistas, sob uma perspectiva da Transposição Didática e a Didática das Línguas, o objeto de ensino compõe um dos três polos que constituem o complexo processo de ensino e de aprendizagem: professor, aluno e saber ${ }^{4}$.

Como a ação de comunicar, de dizer algo a outro alguém é o fundamento do processo de interação social, vemos essa característica como básica e norteadora ao ensino de uma língua, seja ela materna ou estrangeira. Sendo assim, o docente precisa ser preparado para saber elaborar situações enunciativas pelas quais o aluno toma consciência do funcionamento da língua, de modo que seja capaz de ajustar seu dizer a diferentes situações de comunicação, no meio social em que vive. Isso mostra que o atual papel do

\footnotetext{
${ }^{4}$ Mais informações sobre esse tema podem ser lidas no livro Ensino de lingua materna: PCNs, gramática e discurso (WITTKE, 2007).
} 
professor de língua é o de ensinar a ler/interpretar, a falar e escrever por meio de textos, os quais circulam através de gêneros textuais (SCHNEUWLY, DOLZ, 2009, 2010; MARCUSCHI, 2010; DOLZ, GAGNON, DECÂNDIO, 2010; DOLZ, ABOUZAÏD, 2015).

Segundo Dolz, Cordeiro e Schneuwly, em entrevista concedida à autora deste artigo (WITTKE, DOLZ, 2015; WITTKE, SCHNEUWLY, 2016; WITTKE, CORDEIRO, 2016), os saberes a ensinar são conhecimentos didáticos, são os domínios que o professor deve ter sobre a língua portuguesa, sua gramática, seu sistema ortográfico, a história dessa língua, e também conhecimentos sobre a literatura portuguesa, de seus autores. São referentes aos processos de leitura, escrita e uso das normas da língua. Esses são saberes que serão trabalhados em aula: elementos linguísticos e discursivos implicados na ação de comunicar, gêneros orais e escritos, léxico, vocabulário, regras gramaticais. Enfim, são conteúdos específicos para desenvolver a capacidade de ler e produzir textos orais e escritos, em diferentes situações enunciativas. O saber a ensinar é aquele que está nos Parâmetros Nacionais, nos planos de estudo, nos manuais didáticos, são os conteúdos determinados pela instituição de ensino.

Considerando que os gêneros textuais possibilitam a representação das convenções que regem uma família de textos em dada comunidade cultural, eles são definidos como (mega)instrumentos propícios a situações de comunicação e tornam a aprendizagem possível. Para Dolz-Mestre, Noverraz e Schneuwly (2001, p. 12), o gênero de texto "define o que é dizível, sob quais estruturas textuais, com quais meios linguísticos”. Nesse enfoque teórico os gêneros são "instrumentos semióticos, que cristalizam as significações associadas às práticas sociais, cuja associação permite a interiorização de experiências culturais historicamente sedimentadas" (DOLZ; ABOUZAÏD, 2015, online).

Entre as diferentes possibilidades de ensinar a língua por meio de gêneros textuais, destacamos o modelo didático de gênero (MDG) desenvolvido pelos professores DolzMestre, Noverraz e Schneuwly (2001), via sequências didáticas. Esse modelo baseia-se na Didática das Línguas e na Engenharia Didática. Para Dolz-Mestre, Noverraz e Schneuwly (2001), uma sequência didática "tem o objetivo de auxiliar o aluno a melhor utilizar um gênero de texto, permitindo que escreva ou fale de maneira adequada em dada situação de comunicação" (p. 7). 
Esse modelo didático tem norteado as práticas docentes na formação dos professores na Universidade de Genebra, conforme descreveu a professora Cordeiro, quando falou das disciplinas de Francês I e II neste artigo. O MDG é constituído por diferentes etapas, a saber: apresentação da situação de comunicação, produção textual inicial e diferentes módulos (M1, M2, M3, Mn), os quais são elaborados com base no diagnóstico feito pelo professor a partir da leitura da produção inicial dos alunos, e, por fim, produção textual final, momento em que o aluno pode colocar em prática todo o ensinamento desenvolvido em uma sequência didática (SCHNEUWLY; DOLZ, 2010).

\section{O objeto para ensinar}

O professor de língua precisa ter excelente domínio em relação aos saberes necessários a esse ensino, no entanto, tal conhecimento, enquanto conteúdo, não é suficiente, pois, para ensinar, o professor precisa construir também um saber sólido de como agir enquanto docente. Mas quais são os saberes para ensinar fundamentais ao profissional que ensina uma língua? Em primeiro lugar, cabe ao docente saber como fazer a transposição didática das teorias estudadas ao longo do curso de Letras. Ele deve saber como simplificar, transformar esses conhecimentos teóricos em saberes que poderão ser apreendidos por seus alunos, nos diferentes níveis de ensino com os quais atuará. O conhecimento específico do campo para ensinar diz respeito a questões como: quais os dispositivos didáticos mais adequados para ensinar tal ou tal conteúdo? Como selecionálos, ajustá-los ou mesmo construí-los? Quais manuais utilizar em aula? Qual é a melhor sequência didática para trabalhar um dado gênero de texto? Qual suporte utilizar? Quando trabalhar individualmente, em dupla ou em grupos? Saber responder esses questionamentos implica ter tido orientações e experiências dessa natureza ao longo da formação inicial como professor, seja nos estágios ou em outros projetos realizados no meio universitário e nas escolas. Enfim, a dinâmica de grupo e os dispositivos de avaliação também são instrumentos que preparam para o ensino.

Os saberes para o ensino considerados fundamentais são os quatro gestos profissionais a serem realizados pelo docente (SCHNEUWLY; DOLZ, 2009, 2010). Compete ao professor planificar o trabalho da aula; criar situações de ensino adequadas aos objetivos propostos, elaborando dispositivos didáticos; fazer uso da memória da turma, ou seja, ser o mediador entre o que já foi trabalhado e o saber que ainda será visto; regular o 
ensino, fazendo intervenção quando o aluno erra, não somente diante de uma dificuldade, mas também motivando-o a avançar na aprendizagem.

Como se pode ver, os saberes para ensinar são amplos, pois implicam diferentes conhecimentos na área das Ciências da Educação e das Didáticas, tais como gestos didáticos e processo de sedimentação (SCHNEUWLY; CORDEIRO; DOLZ, 2005). Dominando esses saberes, o professor é capaz de se situar no campo profissional, tomando consciência de seu trabalho de educador (NÓVOA, 2002). Ele deve ter noções do funcionamento do processo de aprendizagem para saber lidar com as dificuldades apresentadas pelos estudantes. São, enfim, os saberes que mobilizam o modo de agir docente e são basilares para formar um profissional competente e seguro.

\section{Considerações finais}

Esta reflexão mostra que ainda temos muito a aperfeiçoar no processo de ensino e aprendizagem de uma língua e buscamos apontar alguns caminhos que podem ser seguidos, mas acreditamos que o centro da questão está na conscientização de que a profissão de professor tem duplo estatuto e isso deve ser levado em conta na reformulação das disciplinas de referência (no saber a ensinar) e nas práticas (no saber para ensinar,) voltadas à formação dos docentes da área. O objetivo do presente estudo consiste em despertar no professor formador, no acadêmico de Letras, bem como no professor de língua do ensino básico, a preocupação e o interesse em ver a língua, e também seu ensino, como um processo de interação verbal, no qual um sujeito diz algo para outro, com dada intenção. Ao assumir essa definição de língua, será mais fácil entender a importância de trabalhar com e no texto, desenvolvendo estratégias de leitura e de produção textual oral e escrita.

No entanto, para que isso se concretize, faz-se necessária a reestruturação dos currículos dos cursos de Letras e a criação de espaços para vivenciar o agir docente na sala de aula, seja por meio de estágios ou de projetos de pesquisa, ensino ou extensão. Como defendemos ao longo deste artigo, é preciso repensar as atuais ementas e os programas/conteúdos engessados das disciplinas, e até mesmo as próprias disciplinas, incluindo, em cada uma delas, mesmo nas mais teóricas, a prática da transposição didática e da didática, relacionado seu saber (seja mais voltado a ensinar ou para ensinar) com a ação docente no ensino básico (fundamental e médio), uma vez que formamos (habilitamos) 
professores e não gramáticos, escritores ou linguistas. O papel do professor formador é o de ensinar o futuro docente a construir conhecimento na língua portuguesa nas aulas que ministrará do sexto ano do fundamental até o terceiro ano do médio.

Sob uma abordagem sociointeracionista da linguagem, vemos o ensino de língua como um exercício permanente de desconstrução e construção de textos, atividade que capacita o aluno a interagir com segurança e competência nas complexas situações que o cotidiano lhe proporciona, ao longo de sua vida, dentro e fora dos muros da escola. Nessas condições, é fundamental que o aluno leia e escreva (reescrevendo) frequentemente, aperfeiçoando seu potencial comunicativo, no intuito de construir sentidos, adequando seu dizer a diferentes instâncias discursivas.

Definimos a aula de português como sinônimo de ler e ouvir, escrever e falar textos autênticos e típicos de nosso convívio social, sendo de competência do professor selecionar e eleger os gêneros mais úteis, já que eles são em número ilimitado e por isso impossível abarcar a todos. Para tanto, o professor de língua tem o compromisso de planejar seu trabalho (suas aulas) de modo que essa meta seja atingida, particularmente, explorando o ensino de gêneros textuais. Nessa ótica, a teoria de Transposição Didática, mais voltada aos saberes e suas transformações e configurações, e a da Didática das Línguas, direcionada ao desenvolvimento da linguagem e ao aperfeiçoamento da ação docente, fornecem subsídios teóricos e práticos para desenvolver e aperfeiçoar o ensino de língua na escola.

Sintetizando, o papel do professor de língua materna consiste em selecionar e efetuar a mediação entre o aluno e o amplo e rico material verbal que circula em nossa sociedade, criando oportunidades para que o educando se constitua em um leitor plural: assíduo, crítico e autônomo. E o papel do professor formador é o de criar oportunidades nos cursos de Letras para que o licenciando seja devidamente preparado para cumprir sua função social de mediador entre o saber e o aluno, facilitando a aprendizagem.

A nosso ver, uma das formas de qualificar a formação docente no meio acadêmico brasileiro consiste em centralizar e aumentar a carga horária voltada às disciplinas de didáticas, incentivando a realização de alternância entre a teoria e a prática, por meio de projetos e diálogos entre professor universitário, professor em serviço e acadêmico. Defendemos essa interação, pois, além de enriquecer a formação docente, ela também pode servir de base para muitas pesquisas na área. 


\section{Referências}

ANTUNES, I. Língua, texto e ensino: outra escola possível. São Paulo: Parábola Editorial, 2009.

Gramática contextualizada: limpando "o pó das ideias simples”. São Paulo:

Parábola Editorial, 2014.

BAKHTIN, M. Estética da criação verbal. São Paulo: Martins Fontes, 1992.

BORTONI-RICARDO, S.M. O professor pesquisador. Introdução à pesquisa qualitativa. São Paulo: Parábola Editorial, 2008.

BRASIL/MEC. Parâmetros Curriculares Nacionais (PCNs) $-3^{\circ}$ e $4^{\circ}$ ciclos do ensino fundamental: Língua Portuguesa. Ministério da Educação e de Desportos, Secretaria de Educação Fundamental, Brasília, 1998.

Parâmetros Curriculares Nacionais do Ensino Médio (PCNEM) -

Linguagens, códigos e suas tecnologias. Brasília: Ministério da Educação, 1999.

BRONCKART, J. Atividade de linguagem, textos e discurso. Por um interacionismo sociodiscursivo. São Paulo: EDUC, 2012.

CHEVALLARD, Y. La transposition didactique. Du savoir savant au savoir enseigné. Grenoble: La pensé sauvage, 1985.

DOLZ, J.; GAGNON, R.; DECÂNDIO, F. Produção escrita e dificuldades de aprendizagem. São Paulo: Mercado de Letras, 2010.

DOLZ, J.; ABOUZAÏD, M. Pluralité des genres et singularité du texte: tensions constitutives de la didactique des langues. 2015. Disponível em:

<https://www.leseforum.ch/myuploaddata/files/2015_2_dolz_abouzaid.pdf>. Acesso em: 21 de Jun. 2018.

DOLZ-MESTRE, J.; NOVERRAZ, M.; SCHNEUWLY, B. S'exprimer en français: séquences didactiques pour l'oral et pour l'écrit. V. 3, 5e et 6e. Bruxelas: DeBoeck, 2001. Disponível em: <http://archive-ouverte.unige.ch/unige:34884>. Acesso em: 21 de Jun. 2018.

GERALDI, J. W. (Org.). O texto na sala de aula. São Paulo: Ática, 2006.

GUIMARÃES, A. M. M.; CARNIN, A.; KERSCH, D. F. Caminhos da construção: reflexões sobre projetos didáticos de gênero. São Paulo: Mercado de Letras, 2015.

HALTÉ, J. L'espace didactique et la transposition. Pratiques no 97/98, 1998, p. 171-192.

KOCH, V. I.; ELIAS, V. M. Escrever e argumentar. São Paulo: Contexto, 2016.

MARCUSCHI, L. A. Produção textual, análise de gêneros e compreensão. São Paulo: Parábola Editorial, 2008. 
Gêneros textuais: definição e funcionalidade. In: DIONÍSIO, A. P.; MACHADO, A. B.; BEZERRA, M. A. (Org.). Gêneros textuais \& ensino. Rio de Janeiro: Lucerna, 2010, p. 19-38.

NÓVOA, A. Formação de professores e trabalho pedagógico. Lisboa: EDUCA, 2002.

PERRENOUD, Ph. Formar professores em contextos formais em mudança. Prática reflexiva e participação crítica. Universidade de Genebra. Revista Brasileira de Educação no 12, Set./Dez. 1999, p. 5-21.

PETITJEAN, A. La transposition didactique en français. Pratiques no 97/98, 1998, p. 7 34.

POSSENTI, S. Por que (não) ensinar gramática na escola. Campinas: Mercado de Letras, 2002.

SCHNEUWLY, B.; DOLZ, J. Des objets enseignés en classe de français. Le travail de l'enseignant sur la rédaction de textes argumentatifs et sur la subordonnée relative. Presses Universitaires de Rennes, 2009.

Gêneros orais e escritos na escola. São Paulo: Mercado de Letras, 2010.

SCHNEUWLY, B.; CORDEIRO, G. S.; DOLZ, J. A la recherche de l'objet enseigné: une démarche multifocale. Les Dossiers des sciences de l'éducation nº. 14, 2005, p. 77-93.

SCHNEUWLY, B. Didactique: construction d'un champ disciplinaire. Education et Didactique v. 8, no 1, 2014, p. 13-22.

SCHNEUWLY, B.; HEIMBER, C.; VILLEMIN, R. Les didactiques au centre Formation genevoise des enseignants du secondaire. Revue Suisse des Sciences de 1'èducation $n^{\circ}$ 34 (3), Academic Press Fribourg, 2012.

TRAVAGLIA, L. C. Gramática e interação: uma proposta para o ensino de gramática. São Paulo: Cortez, 2003.

Planejamento de textos para sua produção. In: COELHO, F. A.; PALOMANES, R. (Org.). Ensino de produção textual. São Paulo: Contexto, 2016, p. 87-107.

WITTKE, C. I. Ensino de língua materna: PCNs, gramática e discurso. Santa Cruz do Sul: EDUNISC, 2007.

WITTKE, C. I.; DOLZ, J. Ensino de língua, formação docente e pesquisa: um diálogo com Joaquim Dolz. Fórum Linguístico v. 12, n 4, 2015, p. 986-997.

WITTKE, C. I.; SCHNEUWLY, B. A didática na formação do professor de língua sob a perspectiva do pesquisador Bernard Schneuwly. Calidoscópio v. 14, n 2, 2016, p. 350 361.

WITTKE, C. I.; CORDEIRO, G. S. O ensino de língua e formação docente na perspectiva da pesquisadora Glaís Sales Cordeiro: uma brasileira em Genebra. Signo v. 41, nº 71, 2016, p. 189-203. 


\section{Abstract}

This article derives from the daily practices in teaching Portuguese, through reading, oral, writing and grammar activities, experiences I have had in elementary teaching practice and, later on, in belping in the formation of prospective language teachers in a Federal University in the south of Brazil. Research and practices on both language teaching and language teaching formation of such teachers show the need to reshape the learning/teaching object, as well the way to approach it, which causes an impact on Letter undergraduate courses curricula. This text aims at providing ways to reshape it. Under a sociointeractive and discursive approach, we advocate the formation of a reflexive, independent professional, who is also a researcher. Higher education institutions should be committed to provide future language teachers with the right tools for them to be able to work with the notion of text/text genre, approaching it through an array of strategies that will develop their reading, writing and oral skills (MARCUSCHI, 2008, 2010; SCHNEUWLY \& DOLZ, 2010). We see the importance of didactics and didactics transposition, as well as research, projects and communication with the professors as viable alternatives to achieve the necessary changes.

Keywords: Teaching formation. Research. Verbal interaction

Recebido em: 11/05/2018.

Aceito em: 15/06/2018. 